Прокофьев А.В. Обоснование морали: уточнение одной из задач этической теории // Технологос. - 2021. - № 3. C. 34-44. DOI: 10.15593/perm.kipf/2021.3.03

Prokofyev A.V. Justification of Morality: Clarifying One of the Tasks of the Ethical Theory. Technologos, 2021, no. 3, pp. 34-44. DOI: 10.15593/perm.kipf/2021.3.03

DOI: $10.15593 /$ perm.kipf/2021.3.03

УДК 17.023

ОБОСНОВАНИЕ МОРАЛИ: УТОЧНЕНИЕ ОДНОЙ ИЗ ЗАДАЧ ЭТИЧЕСКОЙ ТЕОРИИ

А.В. Прокофьев

Институт философиии РАН, Москва, Россия

Тульский государственный педагогический университет им. Л.Н. Толстого, Тула, Россия

\section{O CTATBE}

Получена: 09 июня 2021 г. Принята: 07 сентября 2021 г. Опубликована: 10 ноября 2021 г.

Ключевые слова:

мораль, этика, обоснование морали, определение морали, объяснение морали, прояснение нормативного содержания морали, моральный скептицизм.

\begin{abstract}
АННОТАЦИЯ
Рассматривается вопрос о границах между такими задачами этической теории, как определение, обоснование, объяснение морали, а также прояснение ее нормативного содержания. В центре внимания автора находится обоснование морали, под которым понимается создание аргументации, убеждающей разумного агента в необходимости признать моральные требования и на основе этого признания неукоснительно выполнять их. Посылками обоснования служат свойственные любому человеку потребности, а также свойства, от которых невозможно дистанцироваться. Именно с ними аргументы обоснования призваны связать выполнение моральных требований. В итоге даже тот, кто скептически воспринимает моральный долг, но готов соглашаться с разумными доводами, отбрасывает свой скепсис. Непосредственным предметом анализа служат: 1) прецеденты неотрефлексированного смешения обоснования с решением трех других задач этики, 2) осознанные попытки теоретиков превратить объяснение морали позитивными науками в отправную точку или существенный элемент обоснования. Автор статьи считает, что правильные определения морали и ее эволюционные, психологические, социологические объяснения изначально не могут обеспечить «захвата» в отношении убеждений и воли разумного агента. В свою очередь конкретные моральные доктрины и нормативные теории, уточняющие содержание морального долга, формируются на основе предпосылки, что такой «захват» уже имеет место и, значит, сами тоже его не обеспечивают. В связи с этим оказываются невозможны такие концепции обоснования морали, как «эволюционная», «социологическая», «психологическая», а также - «утилитаристская» и «договорная» (во всяком случае в той версии договорной этики, которая представлена у Дж. Ролза). Автор демонстрирует, что попытки некоторых теоретиков преодолеть эти затруднения и придать эволюционной предзаданности морали (Р. Ричардс) или ее упорядочивающему социальному эфрфекту (Р. Кемпбэлл, А.В.Разин) статус отправной посылки обоснования являются неудачными. В каждой из таких попыток за аргументами, апеллирующими к биологии или социологии, скрыто стоят иные аргументы - апеллирующие к выгоде агента или рациональной очевидности.
\end{abstract}

(с) Пнипу

() Прокофьев Андрей Вячеславович - доктор философских наук, доцент, ведущий научный сотрудник, ORCID: https://orcid.org/0000-0001-5015-8226, e-mail: avprok2006@mail.ru.

(C) Andrey V. Prokofyev - Doctor of Science (Philosophy), Docent, Leading Researcher, ORCID: https://orcid.org/0000-0001-5015-8226, e-mail: avprok2006@mail.ru.

Исследование выполнено при финансовой поддержке РФФИ в рамках научного проекта № 20-011-00145 A «Обоснование морали как проблема современной этики (реконструкция, сравнение и оценка теоретических подходов)». The reported study was funded by RFBR, project number 20-011-00145 (Justification of Morality as a Problem of Contemporary Ethics (the Reconstruction, Comparison and Evaluation of Theoretical Approaches))

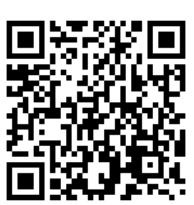

та статья доступна в соответствии с условиями лицензии Creative Commons Attribution-NonCommercial 4.0 International License (CC BY-NC 4.0)

This work is licensed under a Creative Commons Attribution-NonCommercial 4.0 International License (CC BY-NC 4.0) 


\title{
JUSTIFICATION OF MORALITY: CLARIFYING ONE OF THE TASKS OF THE ETHICAL THEORY
}

\author{
Andrey V. Prokofyev \\ Institute of Philosophy RAS, Moscow, Russian Federation \\ Tula State Lev Tolstoy Pedagogical University, Tula, Russian Federation
}

\author{
ARTICLE INFO \\ Received: 09 June 2021 \\ Accepted: 08 September 2021 \\ Published: 10 November 2021 \\ Keywords: \\ morality, ethics, justification \\ of morality, definition of morality, \\ explanation of morality, clarification \\ of the normative content of morality, \\ moral skepticism.
}

\begin{abstract}
The paper deals with borders between different tasks of the ethical theory such as defining, explaining, justifying morality, and clarifying its normative content. The focus of the study is justification of morality, i.e. developing the argumentation that can persuade a rational agent to accept moral requirements and to carry them out. The justification of morality uses as its premise some universal human needs or traits and establishesthe essential tie between them and theprincipled fulfillment of moral duty. The fact that everyone has these needs or traits should convince a rational moral skeptic to abandon her skepticism. The immediate subjects of the analysis are 1) precedents of the unreflecting confusion of justification and three other tasks of ethics and 2) conscious efforts to make the scientific explanation of morality a basis of justification. The author supposes that definitions of morality and its evolutionary, psychological, sociological explanations, no matter how neat and sophisticated they are, can not provide a 'grip' on a rational agent. At the same time, clarifications of the general normative content of morality also can not justify it because they presuppose that this 'grip' is already in place. In this regard, such conceptions of justification as 'evolutionary', 'psychological', 'sociological', 'utilitarian', and even 'contractual' are impossible. The author also shows that efforts of some theoreticians to base their justifications on the fact that human beings are constituted to be altruistic by evolution (R. Richards) or carrying out moral norms has an enormous beneficial effect on society (R. Campbell, A.V. Rasin) are not very successful. The real justuficatory work in these cases is done not by the appeal to biological or sociological facts but by traditional arguments - the benefit of an agent or the self-evidence of intuitions.
\end{abstract}

\section{Введение. Обоснование морали и другие задачи этики}

Обоснование морали является важной задачей этики, или моральной философии. Эта задача тесно связана с общей установкой философского мышления, которую Исайя Берлин обозначил как проверка «исходных посылок общераспространенных (нормальных) убеждений» [1, с. 1-2]. Стремление проверить посылки предполагает возможность того, что они будут признаны ненадежными, хотя и не обязательно ведет к установлению их ненадежности. Философский анализ включает в себя параллельное обсуждение вопросов, почему исходные посылки принимаются людьми и могут ли они быть приняты после их критического обдумывания. Критерии разграничения правильных и неправильных поступков, одобряемых и неодобряемых мотивов или черт характера не являются исключением. Они также требуют проверки на надежность со стороны философского мышления. Поэтому философ, рассуждающий о морали, с неизбежностью пытается определить, существуют ли достаточно убедительные основания для того, чтобы вообще проводить такие разграничения или же проводить их каким-то конкретным образом.

Один из возможных способов самоопределения по отношению к этой проблематике - позиция морального скептицизма, другой - попытка создания какого-то варианта обоснования морали. В последнем случае философ находит определенные аргументы в пользу значимости моральных разграничений для любого человека, который поддается действию рациональной аргументации (любого разумного агента). Аргументация, нацеленная на обоснование морали, должна при этом иметь какую-то точку опоры. Обращение моральной философии к любому разумному аген- 
ту должно строиться по принципу: «Если ты принимаешь X, то ты не можешь не принять обязательность морального поведения, а также формирования мотивов и черт характера, отражающих моральный идеал». Точка опоры обоснования (этот самый Х) должна представлять собой что-то свойственное каждому и, в отличие от моральных обязанностей, не создающее тех конфликтов, которые делают непростым или даже трагическим моральный выбор. Для того чтобы обоснование состоялось, моральный скептик должен в отношении какой-то своей характеристики согласиться с тем, что это неотъемлемая характеристика каждого человека и что он считает ее сохранение безусловно необходимым. Предметом данного утверждения может быть общеразделяемая потребность, общеразделяемая способность или способность, сохранение которой является потребностью: в промежутке от стремления улучшать собственную жизнь (при любом содержательном понимании этого улучшения) до самого по себе признания принудительной силы корректно выстроенной аргументации. От выбора точки опоры зависит (используя терминологию современной этики) наличие или отсутствие «захвата» убеждений и воли того человека, к которому моральный философ обращается в режиме обоснования морали [2, p. 9].

Необходимое уточнение проблемы обоснования возникает в связи с внесением большей ясности в вопрос, что такое мораль. При сугубо формальном, предельно широком ее понимании это набор самых сильных, приоритетных нормативных критериев, определяющих контуры индивидуально-ответственного поведения. Тогда любые представления о практически ориентированном совершенстве личности и о связанных с ним объективно правильных поступках будут по сути своей моральными представлениями. Обоснование морали в таком случае превратится в рассуждение о том, что человеку в принципе необходимо иметь какие-то идеалы и обязанности, несводимые к простому удовлетворению прагматических потребностей.

Однако это понимание морали вызывает существенные нарекания. Оно лингвистически и феноменологически некорректно. Далеко не любые представления о практическом совершенстве человека принято называть моральными убеждениями. С другой стороны, существуют разные моральные доктрины, различающиеся между собой по своему нормативному содержанию. Эти доктрины могут быть продуктами разных культурных традиций или разных философских школ. Можно спорить об их относительных достоинствах, но при этом продолжать считать их именно моральными доктринами, по-разному воплощающими мораль как особое явление культуры и индивидуального опыта. Соответственно, в общую характеристику морали может входить лишь какое-то предельное обобщение ее нормативного содержания, какой-то общий знаменатель моральных ценностей и норм. Мне представляется удачным такой общий знаменатель, как «обязанность содействовать благу другого». Под «другим» при этом подразумевается и отдельный другой человек - моральный реципиент, выступающий в качестве существа, которое равноценно моральному агенту, и разные совокупности других людей, и отдельные живые существа, и, вполне возможно, биологические виды и экосистемы [3, с. 24-28]. Исполнение обязанности содействовать благу другого автоматически предполагает самоограничение агента, ограничение его стремления реализовывать собственное благо. Именно это является одной из самых важных причин того, что мораль приходится обосновывать. Отсюда следует, что обоснование морали предполагает не просто создание аргументации в пользу признания неких высших идеалов, в пользу необходимости существовать в каком-то нормативном поле, но и рациональное подтверждение обязательности альтруистического поведения.

Анализ этической литературы показывает, что задача обоснования морали часто оказывается смешана в ней с другими задачами этики - объяснением морали, прояснением ее нормативного содержания, созданием ее дефиниции. Под объяснением подразумевается раскры- 
тие эмпирических причин возникновения и воспроизводства ценностно-нормативной системы морали. Эти причины могут носить биологический и социокультурный характер, поэтому их установление требует опоры на биологические, социологические, психологические исследования (хотя, конечно, возникающий в итоге философский синтез выходит за пределы подтверждения эмпирических гипотез). Прояснение или конкретизация нормативного содержания морали осуществляются в ходе столкновения конкурирующих моральных доктрин или существующих внутри таких доктрин разных взглядов на конкретные нормативные проблемы. Дефинирование морали предполагает выявление признаков, которые отличают мораль от других форм индивидуального опыта и сфер культуры.

Смешение обоснования с объяснением может происходить в порядке простого предъявления объяснительных гипотез под рубрикой «обоснование», как будто бы корректный ответ на вопрос «Откуда это взялось?» автоматически снимает вопрос разумного агента «Имеет ли это для меня какое-то значение?», заставляя его отвечать «Конечно, имеет!» В других случаях присутствует осознание того, что объяснительные гипотезы, касающиеся генезиса моральных ценностей и воспроизводства альтруистического поведения, автоматически не убеждают разумного агента в необходимости совершать те или иные поступки, однако такое осознание сопровождается уверенностью в том, что эти гипотезы можно успешно встроить в рассуждение, которое будет для него убедительным.

Смешение конкретизации нормативного содержания морали с его обоснованием возникает в силу того, что отдельные моральные доктрины также нуждаются в обосновании, в обосновании того, что именно их интерпретация общего знаменателя морали является наиболее убедительной. Однако такое обоснование (обоснование конкретного набора моральных принципов) осуществляется на фоне уже принятой или доказанной посылки о том, что преодоление агентом желания блага себе и восприятие другого в качестве цели и ценности являются обязательными. В систематических этических теориях одно обоснование, как правило, продолжает другое, но не является тождественным ему.

Наконец, в случае смешения дефинирования морали и ее обоснования нормативное определение этого явления выдается за правомерный ответ на вопрос «Почему мне следует быть моральным (то есть признавать моральные ценности, выполнять моральные обязанности и т.д.)?».

\section{Смешение обоснования морали с решением других задач этической теории}

Я приведу некоторые примеры простого смешения обоснования морали с решением других задач этики. Так, в одной из ранних постсоветских работ по данной теме Абдусалам Гусейнов выделил четыре смысла вопроса об обосновании морали. Первый - выявление морального первопринципа, «источника, из которого река морали берет свое начало», очищение морали «от посторонних скрывающих ее природу наслоений». Второй - подведение под мораль прочной основы («более прочной, чем она сама»), вывод ее из «внеморальной реальности», которая обладает «жестким бытийным статусом (из такого понимания исходят натуралистические и социологические концепции, которые подводят под мораль фундамент инстинктов рода или общих интересов)». Третий - раскрытие «всеобщей основы, объективноистинного содержания морали». Четвертый - демонстрация того, что мораль есть «требование разума, необходимый вывод последовательного мышления» [4, с. 49-50]. Я не буду пытаться разрешить вопрос, в какой мере два последних смысла обоснования представляют собой самостоятельные подходы к нему. Однако мне представляется, что первый является не обосно- 
ванием, а дефинированием морали. Такое дефинирование может быть лишь подготовительным этапом к обоснованию. А второй подход, в особенности с учетом того, что в числе его примеров - натурализм и социологизм, похож скорее на объяснение, чем на обоснование.

В книге Александра Разина «Этика» в общем обзоре концепций обоснования морали перечисляются основные способы ее обоснования, среди которых: 1) утилитаризм; 2) абсолютизм; 3) конвенционализм; 4) натурализм; 5) космизм; 6) социальный детерминизм. Даже при беглом взгляде на этот список нельзя не заметить принадлежности одних из перечисленных позиций к нормативно-этическим позициям, а других - к концепциям объяснения морали. Анализ предложенных в книге характеристик подтверждает это.

Скажем, утилитаризм, если взять его наиболее распространенное определение, представляет собой такую нормативную программу, которая предполагает, что правильным поведением является соответствующее принципу наибольшего счастья наибольшего количества людей (при условии, что счастье каждого человека имеет для принимающего решение агента равный вес). Описывать утилитаризм как самостоятельную концепцию обоснования морали означает создавать неверную его репрезентацию. Разин пишет о том, что утилитаризм, пример «целесредственного подхода» к обоснованию, выводит мораль из «социальных благ, необходимых для удовлетворения материальных и духовных потребностей людей», и рассматривает ее как «путь для достижения счастья» [5, с. 327-328]. Однако в действительности этот, эвдемонистический, подход к обоснованию ценности блага другого человека совсем не обязателен для утилитаристов (для Генри Сиджвика, например, универсальная благожелательность - это аксиома практического разума, для Джон Харсаньи - результат договорной процедуры). Не случайно раздел «Утилитаризм» в книге Разина содержательно заполнен вполне профессиональным анализом нормативных дилемм и противоречий утилитаризма, но мало ориентирован на обоснование морали как таковое (например, в нем нет анализа «доказательства утилитартизма» Джона Стюарта Милля, дуализма практического разума Сиджвика и т.д.).

Что-то похожее происходит и с презентацией абсолютизма и конвенционализма (договорной теории). В разделе «Абсолютизм» довольно много материала именно об обосновании морали, в основном кантовском [5, с. 335-344]. Однако обсуждение абсолютизма как такового (то есть позиции, которая противопоставлена либо релятивизму, либо ситуационизму, в данном случае - это второй вариант) уводит автора в сторону от проблематики обоснования в область нормативных дилемм и противоречий, в этот раз уже деонтологической этики. В разделе «Конвенционализм» договорная этика также представлена как нормативная [5, с. 345-349]. И это верный подход к характеристике этого явления (исключая котракторную концепцию Дэвида Готиера). Скажем, для Джона Ролза основной теоретический вопрос не в том, чтобы показать, почему следует быть справедливым (среди свойств участников исходного положения чувство справедливости присутствует изначально), а в том, чтобы определить набор принципов справедливости. Однако это выводит его теорию из числа концепций обоснования морали. Равным образом этика дискурса проявляет свою специфичность тогда, когда обсуждает процедуры поиска и легитимации моральных принципов, а не саму необходимость их поиска.

Другая часть концепций, представленных в книге Разина, является по преимуществу объяснительной. Возьмем такие тезисы: «неонатурализм пытается сблизить человека и животных, вывести мораль из однотипной психической организации и базовых инстинктов, как полагается, присущих всем живым организмам», «эволюционная этика выводит мораль из общего всему живому стремления к сохранению рода» [5, с. 350-351]. Очевидно, что слово «вывести» подразумевает здесь «обнаружить причины существования». Однако это не обос- 
нование морали. Обоснование начинается там, где «выводится» не само наличие моральных ценностей и норм, а обязательность исполнения нормы для разумного агента, где нечто, сказанное теоретиком о норме, превращается в аргумент для ее исполнения. Психологические (как часть «натуралистических») и социологические («социально-детерминистические») теории также представлены в книге с той стороны, что они раскрывают механику и социальнопсихологический базис морального сознания, а не стимулируют к тому, чтобы быть моральным [5, с. 358-364, 371-377]. Словами Дэвида Юма, они охарактеризованы с точки зрения «анатома», а не «живописца» [6, с. 655]. Скажем, специфику социально-детерминистического подхода задает то, что обращение к общественным отношениям «полагается достаточным и для объяснения процесса возникновения моральных норм, и для характеристики специфики моральной мотивации» [5, с. 372]. У автора, конечно, есть понимание некой недостаточности этих трех концепций именно в сфере обоснования, во всяком случае - в отношении эволюционной этики (например, «[эволюционной этикой] не объясняется, почему человек должен действовать во имя рода и всегда ли такое действие является нравственно оправданным» [5, с. 354]). Но почему тогда необходимо причислять их именно к теориям обоснования?

\section{Превращение научных объяснений морали в фундамент или центральный элемент ее обоснования}

Продолжая анализ того, как представлена проблематика обоснования морали в книге Разина, легко обнаружить не только неотрефлексированное смешение объяснения и обоснования, но и более тонкую теоретическую стратегию. Проанализированному выше историкофилософскому обзору предшествует не связанное с ним тесно рассуждение о том, как данные о происхождении и способах воспроизводства моральных ценностей и норм могут стать важной частью в аргументации, обосновывающей совершение должных поступков. В этом рассуждении обоснование морали уподобляется обоснованию выполнения правил дорожного движения. В случае с правилами дорожного движения отправной точкой является то, что безопасное движение автотранспорта возможно лишь при разных скоростных режимах на разных участках автодорог. Эти режимы предъявлены в виде правил и системы знаков. У участников дорожного движения есть обязанности, определяемые правилами и знаками. Если отдельный индивид - участник движения, то он должен выполнять такие обязанности. Выполнение людьми моральных норм стабилизирует общество и играет ту же роль для его членов, что и безопасность для участников дорожного движения - генерирует обязанность. А некая описательная теория (социальная или социобиологическая) может продемонстрировать, что оно действительно стабилизирует [5, с. 322-323]. Это значит, что данные этой теории превращаются в рычаг обоснования морали.

В современной англоязычной этике есть немалое количество похожих прецедентов случаев отрефлексированного включения данных о происхождении и способах воспроизводства моральных ценностей и норм в ответ на вопрос «Почему мне следует быть моральным?». Особенно распространены они у тех философов морали, которые опираются на фундамент эволюционной теории. Так, Роберт Ричардс полагает, что эволюционная этика может взять на вооружение модель обоснования морали Алана Гевирта, в которой происходит восхождение от неотъемлемых свойств и условий человеческой деятельности к превращению свободы и благополучия другого человека в ценность и цель. Эволюция, по мнению Ричардса, создает неотъемлемый контекст человеческой деятельности - она делает «человеческих существ предрасположенными не только к тому, чтобы совершать действия во благо сообщества, но 
также к тому, чтобы одобрять такие же действия других людей, поощрять их совершение другими» [7, р. 621-622]. Это задает «практическую необходимость для каждого содействовать благу сообщества» (в других случаях Ричардс ведет речь о долге действовать альтруистически) [7, p. 622]. В принципе каждый человек и без обращения к данным теории эволюции имеет набор интуиций, которые поддерживают представление об альтруистическом поведении как должном, но эти данные могут дополнительно свидетельствовать о том, что «люди в целом (с небольшими исключениями) были сформированы так, чтобы одобрять и поощрять альтруистическое поведение» [7, р. 625]. Соответственно, тот кто ведет себя неальтруистично либо имеет моральные интуиции и не может логически обосновать свое поведение (убедительно ответить на вопрос, почему он, будучи человеком, ведет себя не по-человечески), либо не имеет их, и тогда у него нет проблем с логикой, но «мы не можем рассматривать его как человека в полном смысле слова». Он просто лишен «снаряжения», позволяющего ему принимать моральные решения (последнюю по времени создания артикуляцию этого подхода [8]).

Другой вариант предложен Ричмондом Кэмпбеллом. Он считает возможным эволюционно-биологическое обоснование морали при предельно широком понимании последней, то есть как «общераспространенного ядра моральных запретов». В это ядро, по его мнению, входят запреты на инцест, убийство, нападение, несоблюдение данного слова. При этом степень избирательности в отношении реципиентов поведения, регулируемого этими запретами, а также понимание таких явлений, как инцест или убийство, широко варьируются в разных ценностно-нормативных системах. Поэтому Кэмпбелл ведет речь о множественности моралей $[9$, p. 22]. Соответственно, обоснованным в свете эволюционных посылок оказывается соблюдение «какой-то морали» (любой морали собственной группы). Формулировка обоснования такова: «Так как биологическое объяснение существования морали предполагает, что обладание какой-то моралью подавляющим образом улучшает жизненные перспективы каждого члена определенной группы, в сравнении с отсутствием любой морали, то... обладание какойто моралью является оправданным» [9, р. 24]. Хотя эволюционно-биологическое объяснение моральных феноменов оперирует не «жизненными перспективами» или «благополучием» индивидов (что является необходимой посылкой обоснования), а их «приспособленностью», понимаемой как способность оставлять большее, чем в среднем количество потомков, готовых к дальнейшему воспроизводству, Кэмпбелл не считает свое обоснование ненадежным. Причина в том, что увеличение шансов оставить такое потомство приблизительно коррелирует с улучшением благополучия индивидов [9, p. 25].

\section{Причины неудачи этих попыток}

Избегают ли осознанные попытки философов построить обоснование морали на основе ее эволюционно-биологических, психологических, социологических объяснений обвинения в бесперспективном смешении двух разных теоретических процедур? Я думаю, что нет. В каждом из приведенных выше случаев либо вообще отсутствует точка, в которой осуществляется «захват» убеждений и воли разумного агента аргументами против морального скептицизма, либо она упоминается лишь формально. Там, где присутствует такое упоминание, обоснование морали могло бы опираться на какие-то из аргументов, задействованных в тех концепциях, которые прямо ориентированы на трансформацию установок морального скептика, таких как эвдемонизм, стратегический эгоизм, интуитивизм, конструктивизм. Однако стремление теоретиков вывести на первый план своего рассуждения эволюционно-биологические и социологические данные лишь затрудняет решение этой задачи. Эвдемонистическая, эгоистическая, интуитиви- 
стская и конструктивистская аргументация получает стертое и усеченное выражение. При этом некоторые фактические отправные посылки, необходимые для такой аргументации, не нуждаются в подтверждении со стороны эволюционной биологии, социологии, психологии, поскольку очевидны и без применения сложного познавательного аппарата этих дисциплин.

Если обратиться к аргументации Ричардса, то в ее контексте утверждение «человек должен» может означать лишь вероятностное предсказание по поводу поведения людей, а не декларацию универсальной обязательности совершения альтруистических поступков. Ричардс пытается перейти к обсуждению универсальной обязательности альтруизма, но основную роль в этом переходе играет апелляция к моральным интуициям. Ее подкрепление с помощью тезиса, что в эволюционно-биологическом порядке «человек - существо моральное», не может быть хоть сколько-то весомым аргументом в диалоге с рефлексирующим моральным скептиком. Кристин Корсгаард справедливо замечает, что мое знание о том, что эволюционный процесс встроил в мою психику, как и в психику каждого человека, некие альтруистические интуиции, не исключает возникновения сожалений по поводу того, что я обременен этими психологическими особенностями, которые лишь создают мне дополнительные трудности [10, p. 14-16]. Сожалеющий по поводу своих моральных импульсов человек будет либо совершать действия, формально соответствующие моральным требованиям, но в таком состоянии духа, которое обесценивает их в качестве моральных поступков, либо успешно преодолевать импульсивные моральные порывы. Но в любом из этих случаев он не будет считать моральные требования обоснованными. Вероятная реакция Ричардса: «Тогда он не человек!» Однако она вряд ли может серьезно продвинуть дело обоснования. Для того чтобы это восклицание превратилось в убедительный для морального скептика аргумент, скептик должен: а) очень дорожить званием человека, придавать ему высочайшую внутреннюю ценность и б) считать определение человека через склонность к альтруистическому поведению безупречным. А это совсем не обязательное стечение обстоятельств.

Сомнительной является и параллель, которую Ричардс проводит между своей концепцией и конструктивизмом Гевирта. Напомню, что у Гевирта любой рациональный агент просто в силу своей рациональности (он ставит цели и приискивает средства их достижения) нуждается в свободе и благополучии. Эти условия его деятельности являются точкой опоры для обоснования необходимости уважать права на свободу и благополучие других людей. Аргументы обоснования обращены здесь к той способности рационального агента, без которой невозможна его целесообразная деятельность, то есть к самой его рацииональности. Он обязан, поскольку этого требует разум, без применения которого он не мог бы ставить и реализовывать любые цели [11, p. 48-128]. То есть в случае Гевирта аргументация обращена к разуму и опирается в качестве посылки на разумность человека, а в случае Ричардса - обращена к разуму, но в качестве посылки выступают другие свойства, причем такие, которых у кого-то вообще может не быть, а у кого-то они могут быть, но восприниматься как бремя и повод для сожаления. В этом отношении эволюционное «обоснование» изначально обречено, поскольку в нем нет обращения к универсальным потребностям и свойствам.

Разин и Кэмпбелл апеллируют, соответственно, к социальной и эволюционнобиологической полезности повсеместного исполнения моральных норм. Однако что это за полезность? Если это полезность для общества как целого, вне учета собственного интереса агента, то отсылка к ней не может убедить морального скептика, ведь аргумент от пользы общества убедителен лишь для тех, кто изначально ценит эту пользу и, значит, не являются моральными скептиками. Если же это полезность для самого агента в качестве члена общества, 
то аргументация Разина или Кэмпбелла должна быть способна убедить членов общества в том, что они никогда не должны занимать позицию безбилетников или даже более утонченную позицию юмовских «смышленых негодяев». «Смышленый негодяй», как известно, учитывает то, что его благополучие зависит от устойчивости общества, и в большинстве случаев готов воздерживаться от причинения «существенного ущерба социальному единству и союзу», однако если какой-то «акт беззакония или неверности» может привести к «значительному возрастанию его богатства», он совершает такой акт, невзирая на его аморальность [12, с. 272]. Обыкновенный безбилетник, и в особенности «смышленый негодяй», хорошо понимают, что мораль полезна для общества, что соблюдение моральных норм окружающими полезно для них самих, что нарушение ими моральных норм повреждает общественный механизм. К этому пониманию может добавляться специальное знание о генезисе морали как полезного эволюционно-биологического явления и социального института. Однако у исполнения моральных норм, с их точки зрения, нет постоянной связи с их собственными потребностями, ведь повреждение общественного механизма в результате нарушения может быть минимальным, а индивидуальная выгода очень существенной. Соответственно, предъявление им уточненных биологических, социологических, психологических данных о том, как появились и как функционируют индивидуальное моральное сознание и коллективная моральная практика, ничего не добавляет в порядке ответа на вопрос «Почему им следует (всегда) быть моральными?». Научные данные не могут доказать неразрывность и постоянство обсуждаемой мною связи, то есть обосновать тезис, что любое нарушение моральной нормы или даже простое отношение к такой норме как условной ведут к существенному уменьшению благополучия агента. Работу по обоснованию в этом случае могла бы проделать аргументация стратегического эгоизма в духе Готиера $[13,14]$. Аргументация Готиера, конечно, тоже может оказаться в конечном счете неудачной, то есть не лучшим обоснованием морали, но у апелляции к эволюционным, социологическим и психологическим объяснениям морали нет даже шанса на удачу в этом отношении. Она является обоснованием лишь по своей интенции или даже по своей претензии, а не по возможностям.

\section{Заключение}

Итак, концепциями обоснования морали в собственном или узком смысле являются только те этические теории, у которых, судя по их отправным посылкам, имеется надежная точка опоры для развертывания аргументации, обращенной к моральному скептику. Объяснения морали, опирающиеся на данные позитивных наук, не создают такой точки. Их содержание может фигурировать внутри некоторых действительных концепций обоснования (прежде всего, в рамках стратегического эгоизма), однако оно присутствует там в виде дополнительной посылки, не требующей систематических биологических, социологических, психологических исследований. Обыденное знание о существующих в человеческих сообществах кооперативно-коммуникативных отношениях вполне достаточно для выполнения этой роли. Социология, психология и в особенности эволюционная теория оказываются излишними для этого рассуждения или, во всяком случае, использование их данных является недостаточным для того, чтобы называть такие концепции «социологическим», «психологическим» или «натуралистическим» обоснованием морали.

И даже напротив, объяснения моральных феноменов, формирующиеся в позитивных науках, могут быть опорой для скепсиса в отношении морали. Если науки об обществе и человеке могут исчерпывающим образом объяснить существование моральных феноменов без того, чтобы 
это объяснение подкрепляло индивидуальную значимость моральных ценностей, то такая значимость сама попадает под вопрос. Теории, показывающие, как эволюционные и социальнодисциплинарные факторы сформировали и поддерживают уверенность большинства людей в том, что моральные ценности являются объективными и приоритетными, не способствуют, а препятствуют тому, чтобы видеть в такой уверенности результат успешной проверки убеждений на их правильность. Демонстрация тех корней морали, которые не связаны с процедурой удостоверения того, заслуживает ли моральная нормативность нашего признания, не обосновывает мораль, а разоблачает ее. В современной англоязычной этике в связи с этим используется специальный технический термин «эволюционное разоблачение» (evolutionarydebunking) (обзор проблематики (см.: $[15,16])$. По мнению некоторых теоретиков, эволюционное разоблачение касается лишь отдельных моральных принципов, однако другие считают, что оно распространяется на всю мораль (пример такого распространения (см.: [17, p. 179-221, 18]).

Принимая во внимание этот теоретический контекст, я думаю, что анализ тех истоков морали, которые не связаны с признанием агентами объективной значимости моральных ценностей на основе разумных аргументов, можно помещать в рубрику «обоснование морали» только после предварительной оговорки, что некоторые мыслители пытались именно так обосновывать мораль, не отдавая себе отчета в том, что этот подход к обоснованию является изначально негодным.

\section{Список литературы}

1. Berlin I. Introduction to Philosophy // Talking Philosophy: Dialogues with Fifteen Leading Philosophers. - Oxford: Oxford University Press, 1978. - P. 1-27.

2. Scanlon T.M. Being Realistic about Reasons. - Oxford: Oxford University Press, 2014. - 132 p.

3. Апресян Р.Г., Артемьева О.В., Прокофьев А.В. Феномен моральной императивности. Критические очерки. - М.: ИФ РАН, 2018. - 196 с.

4. Гусейнов А.А. Обоснование морали как проблема // Мораль и рациональность. - М.: ИФ РАН, 1995. - С. 48-63.

5. Разин А.В. Этика: учебник для вузов. - М.: Академический проект, 2006. - 624 с.

6. Юм Д. Трактат о человеческой природе // Юм Д. Сочинения в двух томах. Т. 1. - М.: Мысль, 1996. - С. 53-656.

7. Richards R.J. A Defense of Evolutionary Ethics // Darwin and the Emergence of Evolutionary Theories of Mind and Behavior. - Chicago: University of Chicago Press, 1987. - P. 595-628.

8. Richards R.J. Evolutionary Ethics: A Theory of Moral Realism // The Cambridge Handbook of Evolutionary Ethics / Ed. by M. Ruse, R.J. Richards. - New York: Cambridge University Press, 2017. P. 143-158.

9. Campbell R. Can Biology Make Ethics Objective? // Biology and Philosophy. -1996. Vol. 11. - P. 21-31.

10. Korsgaard C.M. Sources of Normativity. - Cambridge: Cambridge University Press, 1996. -287 p.

11. Gewirth A. Reason and Morality. - Chicago: University of Chicago Press, 1978. - 393 p.

12. Юм Д. Исследование о принципах морали // Юм Д. Сочинения в двух томах. Т. 2. - М.: Мысль, 1996. - С. 171-315.

13. Gauthier D.P. Morals by Agreement. - Oxford: Clarendon Press, 1986. -384 p.

14. Gauthier D.P. Why Contractarianism? // Contractarianism and Rational Choice: Essays on David Gauthier's Morals by Agreement / Ed. by P.Vallentyne. - New York: Cambridge University Press, 1991. - P. 15-30. 
15. Sauer H. Debunking Arguments in Ethics. - New York: Cambridge University Press, 2018. $244 \mathrm{p}$.

16. The Cambridge Handbook of Evolutionary Ethics / Ed. by M.Ruse, R.J.Richards. - New York: Cambridge University Press, 2017. - Part III. Against Debunking Arguments. - P. 175-242.

17. Joyce R. The Evolution of Morality. - Cambridge, MA: MIT Press, 2006. - 272 p.

18. Joyce R. Evolution and Debunking // Joyce R. Essays in Moral Skepticism. - Oxford: Oxford University Press, 2016. - P. 109-176.

\section{References}

1. Berlin I. Introduction to Philosophy. Talking Philosophy: Dialogues with Fifteen Leading Philosophers. Oxford, Oxford University Press, 1978, pp. 1-27.

2. Scanlon T.M. Being Realistic about Reasons. Oxford, Oxford University Press, 2014, 132 p.

3. Apresian R.G., Artem'eva O.V., Prokof'ev A.V. Fenomen moral'noi imperativnosti. Kriticheskie ocherki [The phenomenon of moral imperative. Critical Essays]. Moscow, Institut filosofii RAN, 2018, 196 p.

4. Guseinov A.A. Obosnovanie morali kak problema [Justification of morality as a problem]. Moral' $i$ ratsional'nost'. Moscow, Institut filosofii RAN, 1995, pp. 48-63.

5. Razin A.B. Etika: Uchebnik dlia vuzov [Ethics: Textbook for universities]. Moscow, Akademicheskii Proekt, 2006, $624 \mathrm{p}$.

6. Hume D. Traktat o chelovecheskoi prirode [A treatise of human nature]. Sochineniia $v$ dvukh tomakh. Moscow, Mysl', 1996, vol. 1, pp. 53-656.

7. Richards R.J. A Defense of Evolutionary Ethics. Darwin and the Emergence of Evolutionary Theories of Mind and Behavior. Chicago, University of Chicago Press, 1987, pp. 595-628.

8. Richards R.J. Evolutionary Ethics: A Theory of Moral Realism. The Cambridge Handbook of Evolutionary Ethics. Eds. M.Ruse, R.J.Richards. New York, Cambridge University Press, 2017, pp. 143-158.

9. Campbell R. Can Biology Make Ethics Objective? Biology and Philosophy, 1996, vol. 11, pp. 21-31.

10. Korsgaard C.M. Sources of Normativity. Cambridge, Cambridge University Press, 1996, 287 p.

11. Gewirth A. Reason and Morality. Chicago, University of Chicago Press, 1978, 393 p.

12. Hume D. Issledovanie o printsipakh morali [Research on the principles of morality]. Sochineniia $v$ dvukh tomakh. Moscow, Mysl', 1996, vol. 2, pp. 171-315.

13. Gauthier D.P. Morals by Agreement. Oxford, Clarendon Press, 1986, $384 \mathrm{p}$

14. Gauthier D.P. Why Contractarianism? Contractarianism and Rational Choice: Essays on David Gauthier's Morals by Agreement. Ed. P.Vallentyne. New York, Cambridge University Press, 1991, pp. 15-30.

15. Sauer H. Debunking Arguments in Ethics. New York, Cambridge University Press, 2018, 244 p.

16. The Cambridge Handbook of Evolutionary Ethics. Eds. M.Ruse, R.J.Richards. New York, Cambridge University Press, 2017. Part III. Against Debunking Arguments, pp. 175-242.

17. Joyce R. The Evolution of Morality. Cambridge, MA: MIT Press, 2006, 272 p.

18. Joyce R. Evolution and Debunking. Joyce R. Essays in Moral Skepticism. Oxford, Oxford University Press, 2016, pp. 109-176. 